even though a palaeontologist by training, has looked at very few fossils recently. "I spend all my time raising money" he says. Sixty per cent of the museum's \$21-million annual budget (for the main site, the Page and a small history museum out of town) comes from Los Angeles County. But these funds are discretionary, and are increasingly under pressure from the load of mandatory spending on essential services to which the County is committed. The rest comes from earned income, gate receipts, shop revenues and fundraising.

The crunch is likely to continue, so the long-term health of the museum will depend on the private sector. In the short term, decline in county funding has forced Black to make some hard decisions. This year, he has had to cut $\$ 2.2$ million from his budget - well over 10 per cent. Forty-seven positions have been lost by early retirement or redundancy, almost a third of the total staff of 157. Of $42 \mathrm{PhD}$-grade researchers, eight have been laid off.

Black's mission has been to build the museum's endowment, worth just $\$ 10$ million when he moved in; now it is worth $\$ 25$ million. The museum harvests $\$ 0.5$ million of the yield each year; the rest is ploughed back. The museum knows that this thrifty policy might have to change if matters take a leaner turn. Black is meanwhike negotiating three endowed curatorships at $\$ 1$ million each. That may sound hopeful, but it is only a small part of the endowment of $\$ 150-\$ 200$ million the museum would need to become self-supporting. Miracles, they say, take a little longer than the merely impossible.

All the while, Black has to contend with the one question raised by prospective sponsors: if the museum is supported by the County, why should they make any contribution over and above what they pay in taxes? Large corporations, luckily, are keen to provide sponsorship, although these days they prefer to be associated with inner-city education and outreach programmes than blockbusting exhibitions. This is perhaps a blessing. The main museum sits uneasily in its inner-city location, and may depend on good relations with the community for survival. Since the civil unrest, the recession has combined with the local situation to pull gate receipts down by 15 per cent.

Nevertheless, there are good relationships with schools, who are not put off by the museum's scholarly image as much as the casual visitor. And an 'apprentice' programme that brings in high-school students to work on research problems on Saturdays has attracted ethnic minorities and, in turn, favourable interest from sponsors. This programme could expand considerably if there were money to pay for the necessary staff.

\section{Disk drives, hard times}

IN the space of two years in the late 1980 s, researchers at IBM walked away with Nobel prizes for the invention of the scanning tunnelling microscope, and the discovery of high-temperature ceramic superconductors. But within five years, IBM reported the biggest corporate deficit ( $\$ 5$ billion) ever. The cutback in research expenditure this year is expected to be about $10 \%$.

This is curious given that IBM has been a part of computing since the very beginning. IBM's roots in California go back 40 years - the magnetic disk-drive inside every desktop computer was invented here, at IBM in San José. The first research

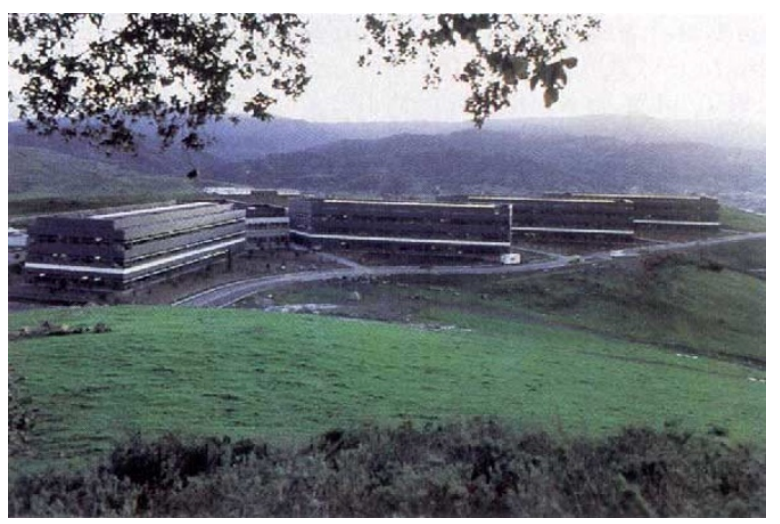

Almadén: IBM's corporate cutbacks must take a toll laboratory in town was a small storefront operation - four buildings on, it is a stylish complex in the green hills out of town. The Almadén laboratory now houses about 650 of the 3,000 people in the laboratories of IBM Research worldwide.

IBM research has traditionally been

ideas into products. Nevertheless, commercial products do come out of such arcana: the STM has proved a very useful research and industrial tool, and fractal geometry (invented by Benoit Mandelbrot, an IBM researcher) is finding its way into such practical things as datacompression algorithms.

\title{
EXOBIOLOGY
}

\section{Recipes for primaeval soup}

EXOBIOLOGISTS are scientists in search of a discipline. Or are they? Exobiology is really a catch-all term for people of diverse backgrounds, connected by a common interest in the origin of life. More than a dozen physicists, chemists, biologists and geologists work at the NASA Ames Research Center under the exobiology umbrella.

One of them is organic chemist Sherwood Chang, who was recruited by NASA Ames while at Stanford in 1967.

That NASA should devote resources to exobiology is a natural extension of its mission. "Life is clearly a planetary phenomenon", says Chang. "Its origin and evolution, at least on Earth, has been intimately connected with the history of the planet itself, and the question of extraterrestrial life therefore must also be directly connected to the origin and the evolution of other planets. If we're to understand how life began on Earth it behoves us to ask similar questions of a planet like Mars, of planets like Venus and other planets accessible to study in the Solar System."

Exobiologists benefit from the results of NASA's space missions, but also contribute their own ideas to the effort. "NASA needs the rationale for the science that it does. Scientists who provide that rationale need NASA's missions, so, yes, it's a two-way street."

Until recently, however, only relatively mature researchers have been able to enter a field thought too controversial for postdocs to risk. This could change, thanks to a new NASA programme, instituted two years ago, to award $\$ 1$ million a year for five years to an institution judged fittest to teach a programme in exobiology. The joint winners were a consortium of the University of California, San Diego, Scripps and the Salk Institute, which pooled their resources to formulate a program. Eventually, this San Diego nucleus will produce a cadre of young exobiologists.

Almost half the NASA-supported exobiologists work in California. Is this because California treats with sympathy matters that others find outlandish? It could be, simply, that many of the advocates of work on the origin of life have been associated with California at some time or other. Stanley Miller (UC San Diego), Leslie Orgel (Salk), Melvin Calvin (Berkeley) and Joshua Lederberg (Stanford) spring to mind, among others. But it may be no coincidence that burgeoning interest in this novel research area matched the rapid growth of higher education in California in the 1960s. Or could it be because, as Chang says, California is "on the edge of things"? 